\title{
Power Balancing and dc Fault Ride Through in DC Grids with de Hubs and Wind Farms
}

\author{
W. Lin and D. Jovcic \\ School of Engineering, University of Aberdeen, Aberdeen, AB24 3UE, UK
}

\begin{abstract}
Power balancing algorithm and dc fault ride through strategy in a DC grid with a DC hub are proposed in this article. LCL dc hub is used in the DC grid to match different voltage levels and to prevent DC fault spreading. An automatic power balancing control is developed for the hub controller, and for DC grid terminals including wind farms and passive AC loads. Collectively these controls enable power balancing for any DC fault without the need for hardware braking systems. The challenges of connecting/disconnecting of DC grid segments and a DC Grid black start with non-isolated dc hubs are resolved with new controls and specific operating sequence. A 3-terminal test dc grid is developed using a 3-port LCL dc hub where one terminal is connected to a wind farm, another terminal is connected to an ac grid and a third terminal to a passive ac load. Simulations on this difficult test system are performed for a range of DC faults, power steps and a black start using PSCAD/EMTDC and results verify conclusions.
\end{abstract}

\section{Introduction}

With the increasing size of offshore power parks and the need for new interconnectors, there has been growing interest in developing DC grids [1]-[6]. The dc grid technology faces the challenges such as the lack of appropriate DC circuit breakers, power flow control difficulty in meshed DC grid, interconnecting DC transmission lines with different DC voltages, protection and reliability issues [1]-[4].

The multiport LCL dc hub [7]-[9] is a new approach in building DC grids which provides possible solution for interconnecting multiple DC grid terminals. However in previous studies, only a single DC hub is operated in isolation and studies are based on steady-state conditions. Unlike with the dc-dc converters employing ac transformers which provide galvanic isolation [10], an inner Inductor-Capacitor-Inductor (LCL) circuit is used in an LCL hub to match the voltages between different ports. The inner LCL circuit enables low power loss, high frequency operation, reduced footprint and weight [7]-[9]. On the downside, this topology brings voltage matching problems during starting (or temporary tripping) of the ports of the hub, which will be studied in this paper.

A particular challenge arises with DC grid terminals that cannot contribute to power balancing. The grid code usually requires the integrated wind farms to remain connected for certain duration of time when the ac or dc grid is at 
fault [11]. During the fault, there will be mismatch between the generated wind power and the power that can be absorbed by the grid, which can result in over-speeding or over-voltages. These issues have not been studied when wind farm is connected to a DC grid constructed by DC hubs.

Two strategies exist in the literature to maintain power balance during grid faults. The common method is to dissipate the surplus wind power using hardware devices such as dynamic braking resistor at the grid level [12]-[13]. Such method requires significant amount of additional capital investment.

Another method is a combination of fast wind power reducing control and the fast dynamic braking system at each wind power generator [14]-[16]. Reference [14] proposed fuzzy logic controller for temporary blocking the VSC converters connected to induction wind generators. AC voltage at the wind farm side is uncontrolled in such case which might bring problems. Reference [15] proposed a method of controlled wind farm ac voltage reduction to zero during ac grid fault. This method is suitable for point-to-point HVDC systems but not necessary for a dc grid as segments of the dc grid can remain operational if one DC Terminal is at fault. Control strategies for AC fault ride through in multi-terminal HVDC grids were studied in [16], while dc fault ride through was not studied.

The present paper will study an automatic power balancing strategy and dc fault ride through of a dc grid constructed with LCL DC hub, and incorporating multiple terminals that cannot actively balance powers.

\section{Test DC grid with the LCL hub}

\subsection{Test DC grid}

DC grid building using DC hubs might be beneficial where DC terminal voltages are different, or where grid protection based on DC CB is not adequate [7]-[8], [17].

Fig. 1(a) shows a 3-terminal dc grid with a 3-port LCL dc hub embedded. This test grid is simple to facilitate simulation, but it is designed to include all operational challenges [18]. Two out of three terminals operate on local power order and have no capability of power balancing. 1.1GW VSC1 is connected to a PMSG based wind farm; $0.6 G W$ VSC2 to an AC grid and 0.5GW VSC3 to a passive resistive load. DC voltage levels at each terminal are different and only terminal 2 has bidirectional power capability but it can take only $55 \%$ wind farm power. The DC cables are of $140 \mathrm{~km}, 200 \mathrm{~km}$ and $35 \mathrm{~km}$ for terminals 1,2 and 3 respectively. Power capacities of each port of the DC hub are different and are respectively $1.1 G W, 0.6 G W$ and $0.5 G W$.

\subsection{Topology and basic operating principles of LCL DC hub}

Fig. 1(b) presents the circuit diagram of the 3-port LCL DC hub [7]. The hub is able to match different DC voltage 
levels at each terminal without the need of employing AC transformer. The proper design of inductors and capacitors of the inner LCL circuit achieves required AC voltage and current stepping between the ports, just like using conventional transformer. This enables optimal power rating for IGBT switches and optimal modulation index for each port. The traditional approach employs high frequency AC transformer to match the voltage difference [19], but this brings the issues of transformer core loss. Also, control and expansion of a high frequency LCL DC hub are simpler than high frequency DC hub based on AC transformers.

Each port of the LCL dc hub is able to fully use the dc voltage and to operate with a rated modulation index of around 1.0 [7]. The modulation method based on square AC waveform as reported in [7] is employed at each port. Any number of phases can be selected, but the 4-phase inner hub circuit is selected to improve the reliability of the hub [8]. Parameters of the 3-port hub are listed in Table 1, in which $M_{\mathrm{p}}$ is the number of phases and $P_{\text {ir }}$ is the rated power per phase for port $i . M_{\mathrm{idr}}$ and $M_{\mathrm{iqr}}$ are the rated $d$-axis and $q$-axis modulation indices that enable zero reactive current at rated operating point at port $i$ assuming modulation index magnitude of 0.95 [7]. The hub is controlled in a rotating $d q$ frame which is common for all ports. In steady state, the coordinate frame is aligned with the angle of phase A voltage of the common AC bus [7].

The operating frequency (frequency of variables in the inner LCL circuit) is selected to be $1.25 \mathrm{kHz}$ which is a good compromise between the size of the passive LCL elements and losses in the hub. Further increase of the operating frequency reduces size of the AC inductors and capacitors but increases switching power loss of the converter [7].

For a fault on any DC line, the hub will inherently maintain current on the faulted port close to rated value, and the un-faulted ports need not to be tripped [7]-[9]. When the faulted port is tripped by opening internal AC CBs (for a permanent fault) the other ports can resume full power operation.

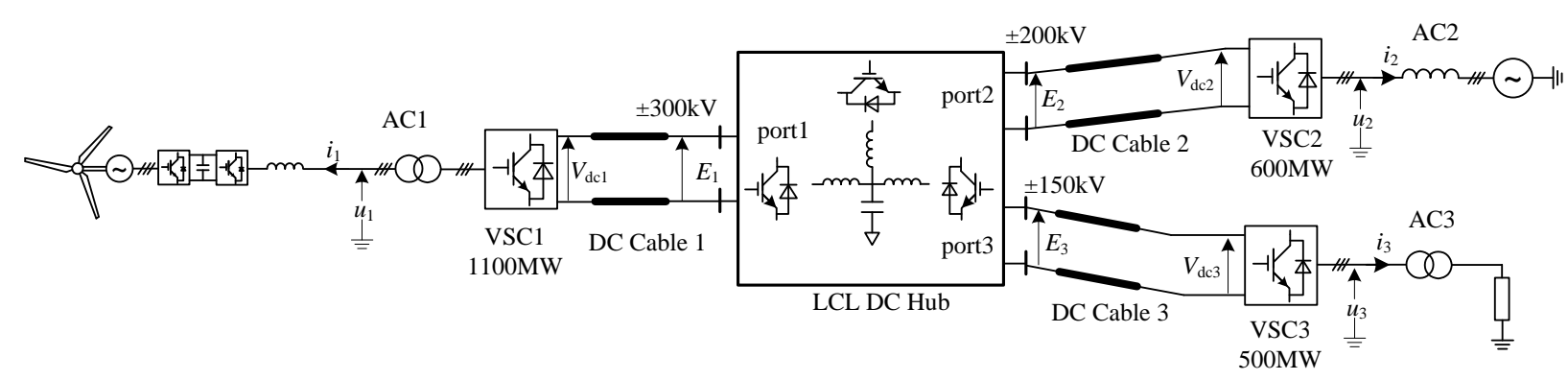

(a) Topology of three-terminal DC Grid constructed by 3-port 4-phase LCL DC hub 


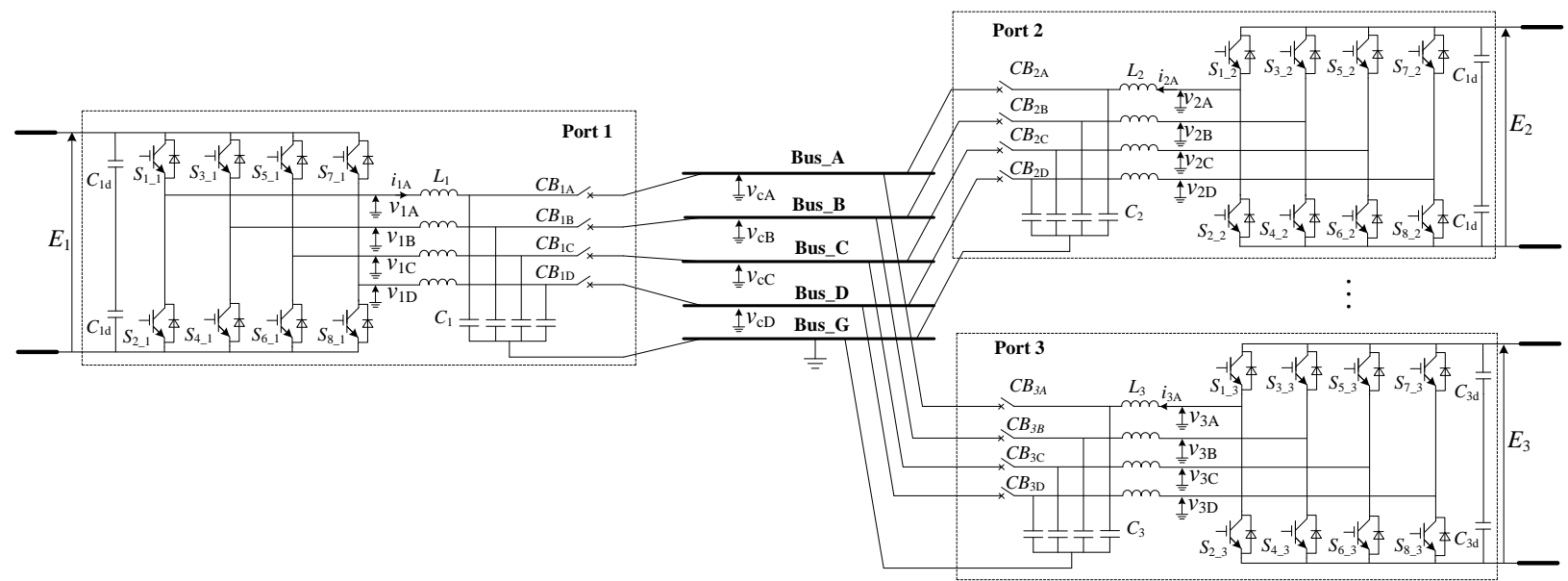

(b) Topology of a 4-phase three port LCL DC hub

Fig. 1. Topology of the test dc grid and the LCL DC hub

Table 1 Parameters of 3-port test dc hub

\begin{tabular}{llll}
\hline Port & 1 & 2 & 3 \\
\hline$V_{\mathrm{idc}}(\mathrm{kV})$ & \pm 300 & \pm 200 & \pm 150 \\
$M_{p}{ }^{*} P_{i r}(\mathrm{MW})$ & 1100 & 600 & 500 \\
$L_{\mathrm{i}}(\mathrm{H})$ & 0.0235 & 0.040 & 0.0389 \\
$C_{\mathrm{i}}(\mathrm{uF})$ & 0.257 & 0.293 & 0.351 \\
$M_{i d r}$ & 0.752 & 0.501 & 0.376 \\
$M_{i q r}$ & 0.580 & -0.807 & -0.872 \\
$V_{i r}(k V)$ & 270.1 & 180.1 & 135.1 \\
$V_{c r}(k V)$ & & 324.1 & \\
\hline
\end{tabular}

\section{Power balance equations inside the LCL DC hub}

\subsection{Capacitor voltage equations}

Assuming all hub variables are expressed in the $d q$ rotating frame, the capacitor voltage equations are [7]:

$$
\begin{aligned}
& K_{c} V_{c d}=\sum_{i=1}^{N} \frac{M_{i d} V_{i r}}{\omega_{o} L_{i}} \\
& K_{c} V_{c q}=\sum_{i=1}^{N} \frac{M_{i q} V_{i r}}{\omega_{o} L_{i}} \\
& K_{c}=\sum_{i=1}^{N} \frac{V_{i r}^{2}}{V_{c r}^{2} \omega_{o} L_{i}}, \quad K_{c}>0
\end{aligned}
$$

where $i$ is the port index, and $N=3, M_{\mathrm{id}}$ and $M_{\mathrm{iq}}$ are the $d$-axis and $q$-axis modulation indices, $V_{\mathrm{ir}}$ and $V_{\mathrm{cr}}$ (which are constants) are respectively the rated RMS value of phase voltage $v_{\mathrm{iA}}-v_{\mathrm{iD}}$ and the common bus $\mathrm{AC}$ voltage $v_{\mathrm{cA}}-v_{\mathrm{cD}}, V_{\mathrm{cd}}$ and $V_{\mathrm{cq}}$ are the $d q$ components of $v_{\mathrm{cA}}-v_{\mathrm{cD}}, \omega_{o}=2 \pi f_{o}$ is the operating frequency of the hub, $L_{\mathrm{i}}$ is the inductor of each port, 
as shown in Fig. 1(b). Note that $V_{\text {ir }}$ is dependent on $E_{\mathrm{i}}$ and therefore different for each port, while $V_{\text {cr }}$ is common for the hub, as shown in Table 1.

It is essential to keep the central capacitor voltage constant, and considering (1), we will maintain $V_{\text {cd }}$ to its rated value if each $M_{\mathrm{id}}$ is kept at its rated value $M_{\mathrm{idr}} . V_{\mathrm{cq}}$ will normally be zero, and it can be adjusted by changing $M_{\mathrm{iq}}$ according to (2).

\subsection{Power balance in the DC hub}

The active power per phase of a port $i$ is [7]:

$P_{i}=\frac{M_{i q} V_{i r} V_{c d}-M_{i d} V_{i r} V_{c q}}{\omega_{o} L_{i}}$

Assume that the capacitor voltage is maintained to be aligned with the $d$ axis, therefore:

$V_{c d}=V_{c}, V_{c q}=0$

where $V_{\mathrm{c}}$ is the RMS magnitude of capacitor voltage. Substitute (5) into (4), a simplified expression of $P_{\mathrm{i}}$ on condition of (5) is

$P_{i}=\frac{M_{i q} V_{i r} V_{c d}}{\omega_{o} L_{i}}$

Equation (6) indicates that $M_{\mathrm{iq}}$ can be used to change $P_{\mathrm{i}}$. If no port of the hub is overloaded, $V_{\mathrm{cq}}$ is maintained to be zero and steady state value of $P_{\mathrm{i}}$ equals to corresponding reference value $P_{\text {iref. }}$.

Sum of all the $P_{\mathrm{i}}$ in (4) will always be zero, therefore:

$V_{c q}=\frac{\sum_{i=1}^{N} \frac{M_{i q} V_{i r} V_{c d}}{\omega_{o} L_{i}}}{\sum_{i=1}^{N} \frac{M_{i d} V_{i r}}{\omega_{o} L_{i}}}$

Each $i^{\text {th }}$ component of the numerator of (7) equals to (6) which is $P_{\text {iref }}$ in steady-state while the denominator equals to $K_{\mathrm{c}} V_{\mathrm{cd}}$ (which is constant) according to (1).

From (7) we conclude that a positive $V_{\mathrm{cq}}$ will show up if the sum of power references in the injecting direction is greater than the power references in the absorbing direction. This positive $V_{c q}$ will inherently act to balance power by reducing power on injecting ports and increasing power on absorbing ports, as seen in (4). At the injecting ports, $M_{\mathrm{iq}}$ will be a positive value, and the positive $V_{\mathrm{cq}}$ will reduce the power of injecting ports accordingly. At the absorbing port, $M_{\mathrm{iq}}$ will be negative and positive $V_{\mathrm{cq}}$ will further increase the absorbed power. The above analysis concludes that a basic inherent power balancing mechanism exists inside the LCL hub. 


\section{DC hub automatic power and voltage balancing}

\subsection{Generic control diagram for each port of the hub}

Fig. 2 shows control diagram of each port of a general $N$-port DC hub. The controller is divided into a $q$-axis controller that outputs $M_{\mathrm{iq}}$ and a $d$-axis loop that outputs $M_{\mathrm{id}}$. The $q$-axis controller is composed of an Active Power Loop, a q-axis damping loop and a $V_{c q}$ loop. The $d$-axis controller is composed of a $V_{c d} l o o p$, a $d$-axis damping loop and a $M_{\mathrm{idr}} \cdot L P F$ and $B P F$ respectively stand for low pass filter and band pass filter.

Each port of the hub employs the same controller. Depending on the function of a port, the $M_{i q}^{\text {power }}$ may be generated by different active power loops. The $F_{\text {mode }}$ is used to select the function of each port. With $F_{\text {mode }}=\mathrm{I}$, a port is used to control its transmitted DC power (from DC side to AC side of a port) to its reference value $P_{\text {iref }}$. With $F_{\text {mode }}=\mathrm{II}$, a port is used to control its DC terminal voltage $E_{\mathrm{i}}$, such as port1 and port3 in the test system of Fig. 1 . With $F_{\text {mode }}=$ III, a port acts as a power balancing port to balance the active power of the hub, such as port2 of Fig. 1.

The $d$-axis and $q$-axis damping loops are used to provide damping during transients. The oscillating components may appear in the DC hub because of global LCL and local LC resonances [7]. The oscillating component is extracted by passing $V_{\text {cdpu }}$ and $V_{\text {cqpu }}$ through a band pass filter (BPF).

The $V_{\mathrm{cd}}$ loop is used to control the capacitor voltage based on (1). This control is only required during transients which will take effect according to (1) only if $V_{\mathrm{cd}}$ deviates from the rated value. In normal operation, each $M_{\mathrm{id}}$ will be close to $M_{\mathrm{idr}}$ where $M_{\mathrm{idr}}$ is the rated value of $M_{\mathrm{id}}$.

\subsection{Active power balancing of the hub}

The $V_{\mathrm{cq}}$ loop is used for active power balancing of the hub, which is essentially a droop controller. As analyzed in section 3.2, a positive $V_{\mathrm{cq}}$ appears if there is more injecting power than absorbing power of the hub. The $V_{\mathrm{cq}}$ loop outputs a negative $M_{\mathrm{cq}}$ in this case and a negative $M_{\mathrm{icq}}$ is superimposed on the ports with $F_{\text {mode }}=$ I or II. For absorbing power ports, the $M_{\mathrm{iq}}$ will be decreasing and if port is at maximum power $M_{\mathrm{iq}}$ hit its lower limit of $-1.05 M_{\mathrm{iqr}}$. For injecting power ports, the negative $M_{\mathrm{icq}}$ reduces $M_{\mathrm{iq}}$ so as to actively reduce the injected power. A power balanced state could therefore be achieved by actively reducing the power output from the injecting ports. The case of more absorbing power than injecting power can be analyzed in a similar way. 


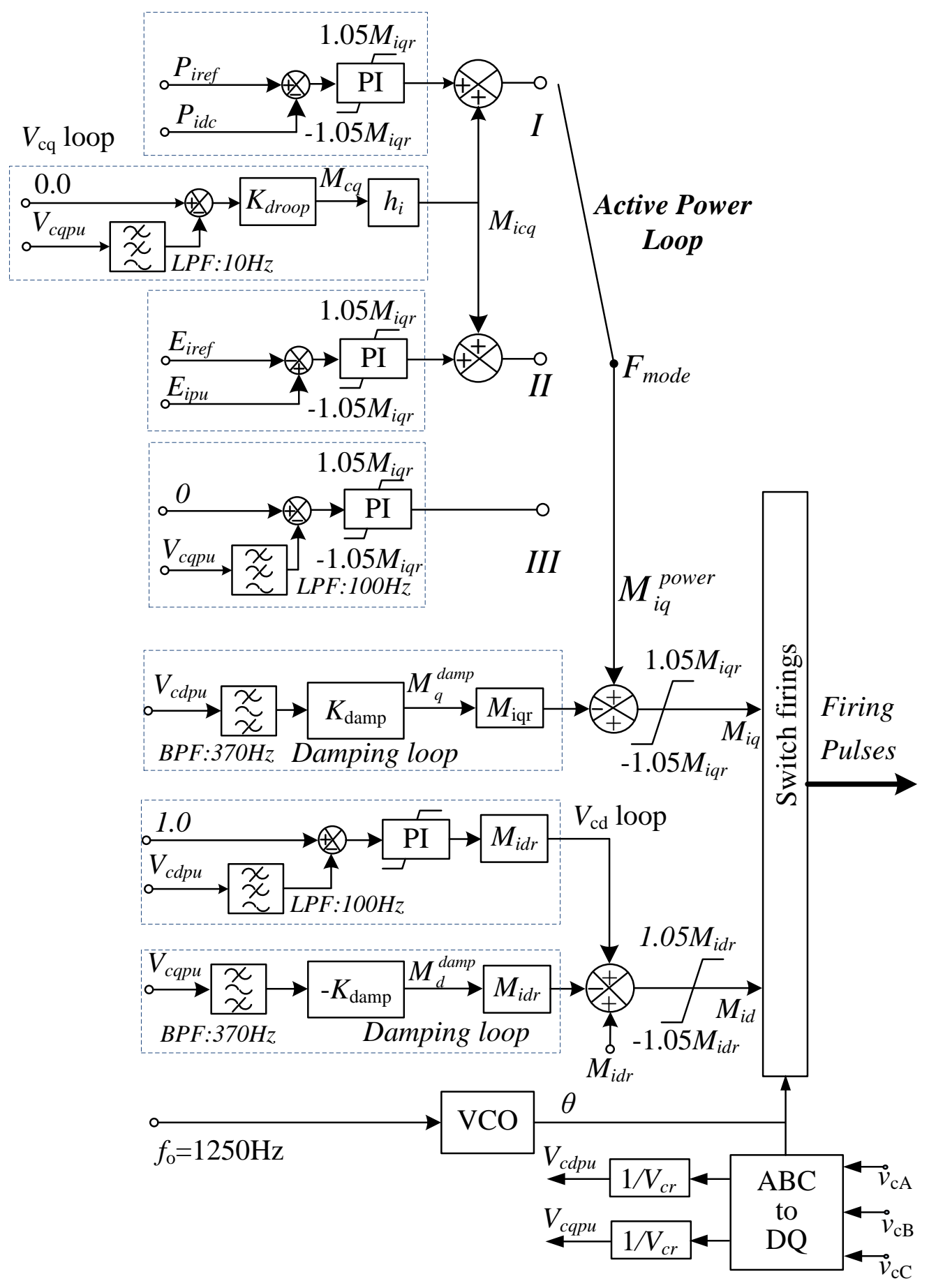

Fig. 2.Generic control of a port of the LCL DC hub

\section{Automatic power balance of the DC grid}

5.1 Grid power balance challenge 
For the 3-terminal de grid shown in Fig. 1(a), VSC1 and VSC3 will be used to control the AC voltage and frequency of their corresponding ac networks [20]. Correspondingly, port1 and port3 of the LCL dc hub will be configured to control the dc voltages $\left(E_{1}\right.$ and $\left.E_{3}\right)$ of DC cable1 and DC cable2. Port 2 will then be used to maintain internal power balance of the hub while VSC2 is configured to control the dc voltage $\left(V_{\mathrm{dc} 2}\right)$ of DC Cable2.

If a fault happens at port 3, DC cable3 or VSC3, port 2 will not be able to absorb the full wind power. The inner hub power balancing of section 4 will decrease the port 1 power to protect port 2 from over loading. However, wind farm is still generating full power, and as a result overvoltage happens at dc cable 1 . In the meantime, the dc voltage of port 2 will be increased considering that VSC2 may not be able to evacuate all power from port 2, because of low rating. Such scenario may lead to cable 2 over-voltage and could damage port2, DC cable 2 and VSC2.

If a fault happens at port2, DC cable 2 or VSC2, only the wind power will be used to provide the power supply to the passive AC load at terminal 3 of the dc grid, as the wind power is the uncontrollable power source and the passive AC load is uncontrollable load. An automatic power balance between the wind power and the passive AC load needs to be achieved to prevent overvoltage at DC cable 1 during high wind power profile or prevent collapse of dc voltage at cable 3 during low wind power profile.

In case that fault happens at port 1, DC cable 1 or VSC1, only the AC source at terminal 2 will supply active power to the passive load at terminal 3. Since VSC2 has higher power rating than VSC3, fault at the wind power side will not bring significant disturbance to the dc grid.

In case of a fault inside the hub, port3 will not be able to transmit the power required by the resistive load. DC voltage of port 3 will be decreased and therefore the AC voltage of the load will decrease. A power balance may be achieved at lower voltage depending on the control mode at VSC3. If VSC3 prevents the current exceeding the rated value, as it is case with all converters, then power will be proportional to DC voltage.

\subsection{Automatic power balancing between port1 and wind farm}

VSC1 controls the voltage and frequency of the AC1 system (offshore isolated AC grid connected to wind farm). The control diagram for VSC1 is shown in Fig. 3(a), majority of which is well understood from the literature [20]. The proposed supplementary power balancing control is shown in the dashed box of Fig. 3(a).

In normal operation, $V_{d c 1}^{p u}$ will always be lower than 1.05. Output of the supplementary controller will therefore be saturated at 0 and it will not affect the normal operation. In the case of system faults (like faults on port 2 DC or AC system) there will be reduced power transfer capability of the hub, and $V_{\mathrm{dc} 1}$ will be increased to be higher than 1.05 . 
Supplementary controller of Fig. 3(a) will output a negative $\Delta U_{1 d}^{\text {ref }}$ that is added to $U_{1 d}^{\text {ref }}$ to reduce the AC voltage of VSC1. This will result in reduced terminal power at $V S C l$ and dc overvoltage will be avoided. Once the hub resumes its power transfer capability, $E_{1}$ will be controlled to $1 \mathrm{pu}$ by port1, $V_{\mathrm{dc} 1}$ will be lower than $1.05 \mathrm{pu}$, the $\Delta U_{1 d}^{\text {ref }}$ of Fig. 3(a) will be restored from negative value up to zero.

For variable speed wind power generators, inner current control loop will normally be used to prevent overcurrent of the power converters [21]-[22]. In the case of reduced AC voltage, the power converters will increase the output current until it reaches the upper limits. Power transfer capability of the converter is then reduced because of the reduced AC terminal voltage. The local dynamic braking resistor [12] of each wind power generator will automatically take action to ensure there will not be over-speed if the dc grid is not able to absorb all the power from wind power generator [14]. However the proposed control avoids dynamic braking at wind farm level.

During variable wind power, the AC voltage in the wind farm will be changed to certain extent; the $V_{\mathrm{dcl}}$ will also be changed. Since $E_{1}$ can be controlled to 1 pu by portl in steady state, $V_{\mathrm{dc} 1}$ raises to the value of $E_{1}$ plus the DC voltage drop across the DC cable1 which will not be higher than 1.05pu. Also, since a VSC converter is able to control its terminal AC voltage while DC voltage is at rated value, the supplementary control will not be activated in normal operation such as variable wind power.

\subsection{Automatic power balancing between port3 and the resistive load}

Similarly as VSC1, the main task of VSC3 is to control the AC voltage and frequency of the AC network AC3. Its control structure is shown in Fig. 3(b). The dashed box of Fig. 3(b) shows the supplementary controller of VSC3. In normal operation, $E_{3}$ will be controlled by port3, $V_{\mathrm{dc} 3}$ will be higher than $0.97 \mathrm{pu}, \Delta U_{3 d}^{\text {ref }}$ will be saturated at 0 and not interfering in normal operation of VSC3.

In the case when port 3 not able to transmit required power to VSC3, port3 will no longer control $E_{3}$ to $1 \mathrm{pu}$, and $V_{\mathrm{dc} 3}$

reduces. Once $V_{\mathrm{dc} 3}$ reduces to be lower than $0.97 \mathrm{pu}$, a negative $\Delta U_{3 d}^{\text {ref }}$ will be superimposed at $U_{3 d}^{\text {ref }}$ to reduce AC voltage at VSC3 so as to reduce the power extracted by VSC3. This results in degraded performance, rather than system collapse and tripping of port3-VSC3.

The test case of Fig. 1 is specially designed to test all the difficult scenarios, and port 3 is a pure resistive islanded load. If VSC 3 is connected to an active AC grid and operate in the active power control mode, a simpler power balance control can be achieved by adding $\Delta U_{3 d}^{\text {ref }}$ to the power reference in grid $3 P_{\text {iref. }}$. 


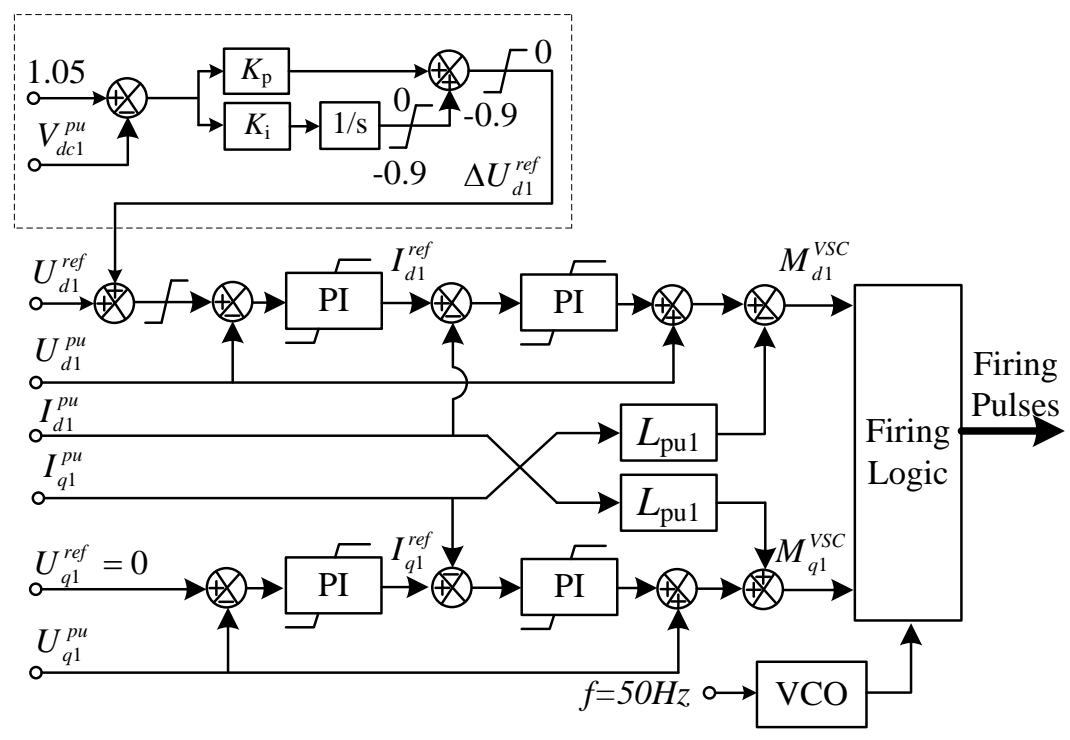

(a) Control diagram of VSC1

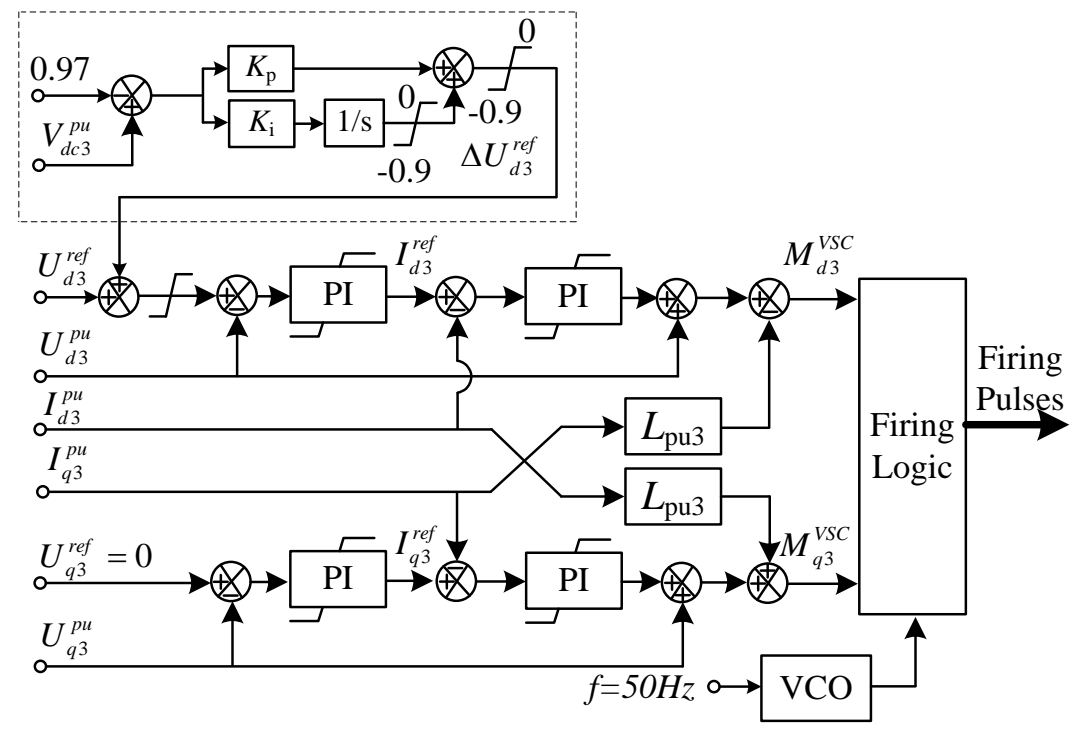

(b) Automatic power balancing controller installed at VSC3

Fig. 3. Control diagram of VSC1 and VSC3 with power balancing controller.

\subsection{Finite state machine of power balancing process for a general DC grid}

Fig. 4 gives a finite state machine [23] of the power balancing process for a general DC grid which may include more than 2 power terminals and more than 1 balancing terminal. The system will normally be operated at power balanced state but it can move to one of the two unbalanced power states. Normally, the balancing terminals (like terminal 2 in the above test system) will be able to balance the power through DC voltage control which may also include some droop control. This method will not be adequate if some terminals or some ports are at fault. 


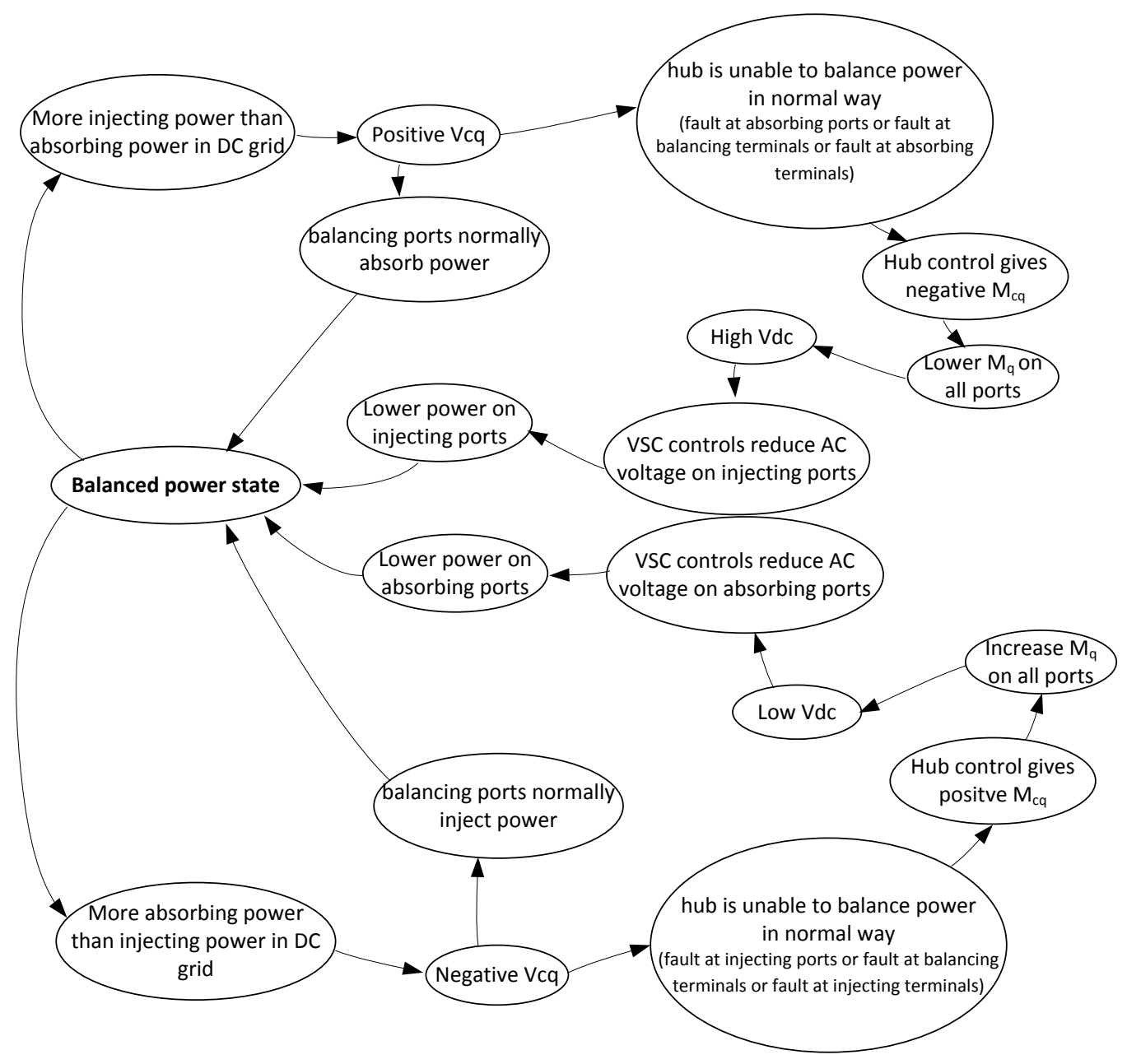

Fig. 4 Finite state machine of the DC grid power balance.

If there is more injecting power, but balancing ports are unable to balance power, then positive $V_{\mathrm{cq}}$ will show up in the hub. With a positive $V_{\mathrm{cq}}$, the $V_{c q}$ loop in Fig. 2 automatically outputs a negative $M_{\mathrm{cq}}$ to reduce the $M_{\mathrm{iq}}$ at all the ports. The $M_{\mathrm{iq}}$ at the absorbing ports will be bounded at the lower limit of $-1.05 M_{\mathrm{iqr}}$ because of a fault in the absorbing capacity in the DC grid, while the $M_{\mathrm{iq}}$ at the injecting ports will continue to decrease so as to decrease the power at the injecting ports. DC line voltage associated with the injecting ports will be automatically increased as the injecting port is not able transfer all the DC power fed from external injecting terminals. Once the DC line voltage is higher than 1.05pu, the supplementary control in Fig. 3(a) exits the saturation state and will reduce AC voltage at the injecting ports which will reduce power injected to the DC grid. This will lead to power balance state. The process is similar for more absorbing power. 


\section{Restart sequence of the LCL DC hub and DC Grid}

\subsection{Overvoltage challenges for dc hub restart after a fault}

Normally, in a DC hub, the AC voltages at each port can be different and correspond to rated voltages of the connecting DC systems. In the test system, port 3 equipment is rated for $300 \mathrm{kV}$ but the port 1 is rated for $600 \mathrm{kV}$ and the central capacitor voltage will be $20-30 \%$ higher than the voltage of the port1[7]. The voltage stepping between ports is achieved by the voltage drop across inductors caused by controlled AC current [7] inside the hub. If the current is not running, then Thevenin open circuit voltage (capacitor voltage) applies at the port. This may lead to port overvoltage only if there is no DC voltage on the particular port.

Another very important operating situation arise in the case that the firing pulses of a port are blocked, but the port $\mathrm{AC} \mathrm{CB}$ (shown in Fig. 1(b)) is closed as it might be the case for recovery after a serious fault, in which case the port becomes a diode bridge. If DC side of the particular port is in open circuit condition, the DC voltage at the port will be charged up to the peak line-line capacitor voltage which is calculated as.

$V_{\text {peak }}^{\text {line-line }}=2 \sqrt{2} V_{c r}$

The actual value for the capacitor voltage can be calculated knowing that port AC voltage $V_{\text {ir }}$ is directly linked to the DC voltage according to [7]:

$V_{i r}=\frac{4 M_{i r} E_{i}}{\sqrt{2} \pi},\left(M_{i r} \approx 0.95\right)$

The capacitor voltage $V_{\text {cr }}$ is typically $20 \%$ higher than the highest $V_{\text {ir }}$ The peak line-line value of the four-phase common AC bus voltage is therefore:

$V_{\text {peak }}^{\text {line-line }}=2 \sqrt{2} V_{c r}=2 \sqrt{2} * 1.2 * \max \left(\frac{4 M_{i r} E_{i}}{\sqrt{2} \pi}\right)=\frac{4.8 M_{i r}}{\pi} \max \left(2 E_{i}\right)$

Therefore, for the port with highest $E_{\mathrm{i}}$, there will be about $45 \%$ over-voltage. For a port with low $E_{\mathrm{i}}$, significant over-voltage may happen if DC side is open circuit while IGBTs are tripped.

If the IGBTs are operating, closed loop DC voltage control and power balance control will ensure firm DC voltage and this implies that there is no port overvoltage. From the above analysis, it is concluded that when IGBTs are tripped for ports with its DC side open-circuit, the port AC CB should also be tripped thus isolating the port from the hub.

It is also essential that the port AC CB is located on the central capacitor side (not on the converter side) of the LC circuit since this provides some delayed voltage rise when connecting the port to the energized hub. As it will be 
shown in the simulation section, a port can be operated as a diode bridge for up to $20 m s$ which is sufficient to enable simple coordination between AC CB and IGBT tripping.

\subsection{Restart of the LCL DC hub}

To avoid the port overvoltage during restarting, firing pulses of IGBTs should be enabled as long as the port is connected to the hub. In practice this can be achieved with simple interlocking logic at each port. If this approach is followed any port can be used to energize the hub (including the high voltage port).

A DC hub can be restarted using the following procedures:

1) Before restarting the hub, at least one port is supplied with DC voltage. Activate port control at zero power. The hub capacitor voltage $v_{c}$ may not reach its rated value as the closed loop hub capacitor voltage control has not been put into service at this state.

2) Enable the firing pulse of each port and increase each $M_{\mathrm{id}}$ gradually to its rated value $M_{\mathrm{idr}}$. This will establish all other DC voltages but their values will be below rated values.

3) Enable the closed loop controller of Fig. 2 on all ports to bring up AC capacitor voltage and DC voltage of each port to their respective rated value.

\subsection{Connecting a standby port to an operating hub}

If the DC system of the standby port is energized, the standby port could be operated as one port hub to synchronize its capacitor voltage with the central capacitor voltage of the hub. Control of the capacitor voltage of the standby port can be confirmed from (1) considering hub as 1-port $(N=1)$. After synchronization, the AC CB of the standby port will close.

If the DC system of a port is not energized, the standby port could be started by firstly connecting to the common buses through its AC circuit breakers, and then enabling the firing pulses of IGBTs. A small delay is allowed between AC CB closing and IGBT activation, as discussed. Once IGBTs are activated, DC voltage of the port will be increased by its controller such as demonstrated in Fig. 2(a) with $F_{\text {mode }}=$ II. This method is applied for starting dead DC system using DC hub.

\subsection{Malfunction of the AC circuit breaker of the $\mathrm{Hub}$}

The hub relies on the AC circuit breaker to isolate the faulted DC transmission line from the AC circuit of the hub. This section will analyze the impact of malfunction of the AC circuit breaker on the security and operation of the hub. In the case that $\mathrm{AC} \mathrm{CB}$ of a faulted port fail to open, the IGBTs of the faulted port can remain operating or be tripped 
as the design of the LCL DC hub ensures that there will be no damaging overcurrent at the faulted port and the DC voltage of the faulted port will be clamped around zero [7],[9].

According to (1), the $d$-axis common bus AC voltage with a port $f$ subjected to dc fault can be calculated by

$V_{c d}=\frac{1}{K_{c}}\left(\sum_{i=1}^{N} \frac{M_{i d} V_{i r}}{\omega_{o} L_{i}}-\frac{M_{f d} V_{f r}}{\omega_{o} L_{f}}\right)$

Where index $f$ indicates the $f^{\text {th }}$ port is subjected to DC fault. The $V_{\text {cd }}$ will be lower than the nominal value calculated from (1) but still maintains quite high value. The hub is still able to maintain partial power transfer capability even with the DC fault consistently presented at one port without being isolated by the AC CB.

\section{Test System simulation results}

\subsection{Connecting un-energized port3 to operating hub}

Fig. 5(a)-(b) presents simulation of connecting a standby port 3 to an operating hub. The system of Fig. 1(a) was running as a 2 -terminal de system with $600 M W$ wind power before 2.0 s. The $A C 3, V S C 3$, DC cable 3 and port 3 were dead networks before 2.0s. At 2.0s, AC CB of port3 is connected to the common AC bus of the hub.

Fig. 5(a) shows the dc voltage $E_{3}$ where "blocked" represents that IGBTs of port3 are blocked after connection of AC CB, "Delay40ms", "Delay20ms" and "No Delay" represents IGBTs are enabled 40ms, 20ms and no delay after connection of AC CB. IGBTs of VSC3 are blocked in this test, but similar results are obtained if VSC3 is operating.

Fig. 5(a) shows that there will be dc over voltage if the enabling of IGBTs of port3 is prolonged more than $20 m s$ after closing the AC CB. Fig. 5(b) gives curves of ac currents of port3, where only the phase currents with largest peak value are shown. We can see that there is 2 pu overcurrent only if enabling IGBTs is delayed $40 m s$ after operation of $\mathrm{AC} \mathrm{CB}$.

We can conclude from Fig. 5(a) and (b) that there will not be over voltage or over current if the IGBTs of an un-energized/standby port is enabled timely(within 20ms) after operating the AC CB of a port.

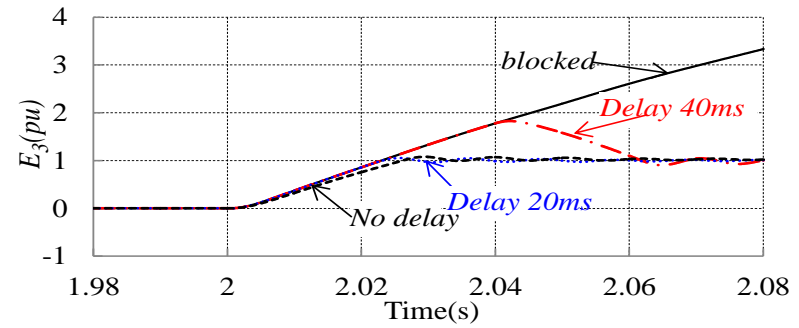

(a) DC voltages when connecting port3 to operating hub

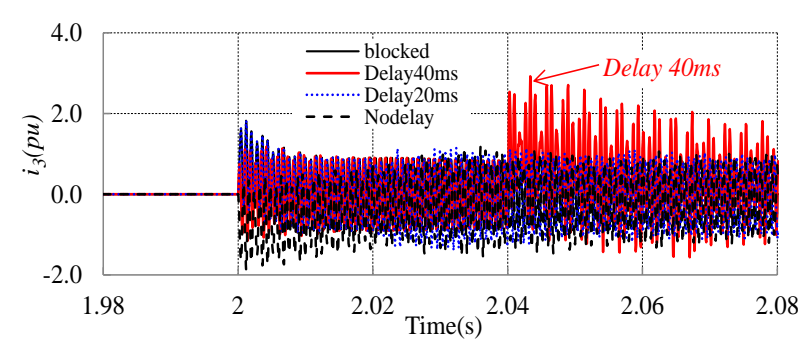

(b) Maximum AC currents when connecting port3 to operating hub

Fig. 5. Simulation results of starting a port 


\subsection{Simulation of restart of the DC Grid}

Assuming that a serious fault has brought down the whole system Fig. 6 shows the key variables of the DC grid restart process. Before the startup, all the DC capacitors are discharged.

- 0-0.1s: Only AC2 is alive and VSC2 diodes establish $E_{2}$.

- 0.1s: Enable firing pulses of VSC2 and VSC2 controls $V_{\mathrm{dc} 2}$;

- 0.5s: Close all AC CBs in the hub and enable firing pulses on all ports simultaneously (non-simultaneous in the range of tens of $m s$ will not bring over-voltage to the lower voltage ports).

- $0.5 \mathrm{~s}-0.7 \mathrm{~s}:$ Each $M_{\mathrm{id}}$ is ramped to its respective rated value.

- $0.7 \mathrm{~s}$ : port1 and port3 begin to control $E_{1}$ and $E_{3}$ while Port2 begins to control $V_{\text {cq. }}$. At this stage the DC hub is energized with all DC and inner AC voltages at $1 p u$ and the hub operates at zero power.

- 1.2s: Firing pulses of VSC1, VSC3 and wind power generators are enabled and controls activated.

- 1.7s: Key variables of the DC grid settled to rated values and power transfer resumes.

We can see from Fig. 6 that a dead DC grid can be brought to normal operation and that DC hub can be used to energize dead DC systems. Even a passive AC system (AC3) can be energized from DC side using DC hub. It should be noted that during $0 \mathrm{~s}-0.1 \mathrm{~s}, \mathrm{AC}$ voltage at $\mathrm{AC} 2$ is used to charge $\mathrm{DC}$ cable 2 through the diodes. Since peak line-line voltage of $\mathrm{AC} 2$ is lower than $E_{2}$, there will not be overvoltage (as in the case of using the common bus $\mathrm{AC}$ voltage to charge an open circuit low voltage port through diodes) during the free-charging stage.

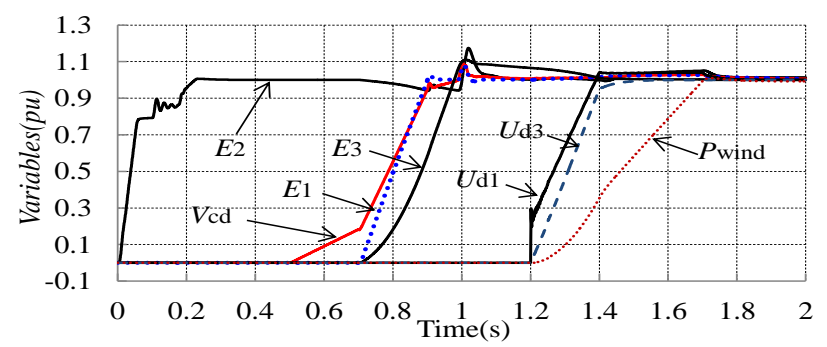

Fig. 6. Simulation results of starting a DC grid constructed by the LCL DC hub

\subsection{Response to unbalanced power orders in steady state}

Fig. 7 shows system response to step change of load (system 3) and then step in wind power (system 1). Two disturbances are applied successively. 1) A first disturbance of reducing the resistive load from 500MW to 250MW is applied at 3.0s, and therefore there is surplus power entering the hub. This is a difficult scenario since port 2 is at full power and it cannot further increase power. 2) A further disturbance of stepping the wind power from 1100MW to $330 \mathrm{MW}$ is applied at $3.5 \mathrm{~s}$. 
Fig. 7(a) shows that AC power of VSC1 and VSC3 reach their respective reference values in steady state. Rectifying mode is defined as positive power direction for $P_{\text {ac1 }}$ and inverting mode is defined as positive power direction for $P_{\text {ac2 }}$ and $P_{\text {ac3 }}$. At 3.0s the controller of Fig. 3(a) is activated and the output wind power reduces. Fig. 7(b) shows that the AC voltage at VSC3 is maintained to its rated value. It is also seen that the power balancing control of VSC1 reduces AC voltage at VSC1 after 3s which achieves power balancing. The wind farm voltage returns back to $1.0 \mathrm{pu}$ at $3.7 \mathrm{~s}$ when the hub restores to balanced state

Fig. 7(c) shows the $M_{i q}^{\text {power }}$ of each port. $M_{1 q}^{\text {power }}$ and $M_{2 q}^{\text {power }}$ are saturated during the time span of 3.0s to 3.5s, which is expected according to controllers in Fig. 2, and they move out of saturation after the power orders of the DC grid restores to balanced state.

Fig. $7(\mathrm{~d})$ shows that the values of each $M_{\mathrm{iq}}$ and $M_{\mathrm{cq}}$. Steady state value $M_{\mathrm{cq}}$ is nonzero only during the time span of $3.0 \mathrm{~s}$ to $3.5 \mathrm{~s}$ when there is more injecting power order than absorbing power. $M_{\mathrm{cq}}$ restores to zero in steady state once the power order of the DC grid is balanced.

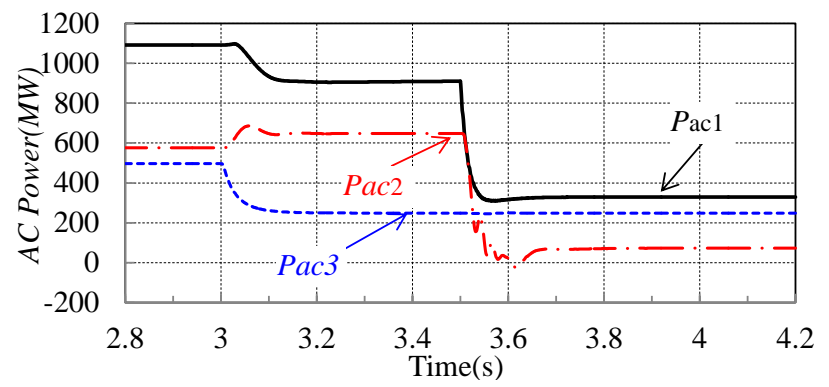

(a) AC power

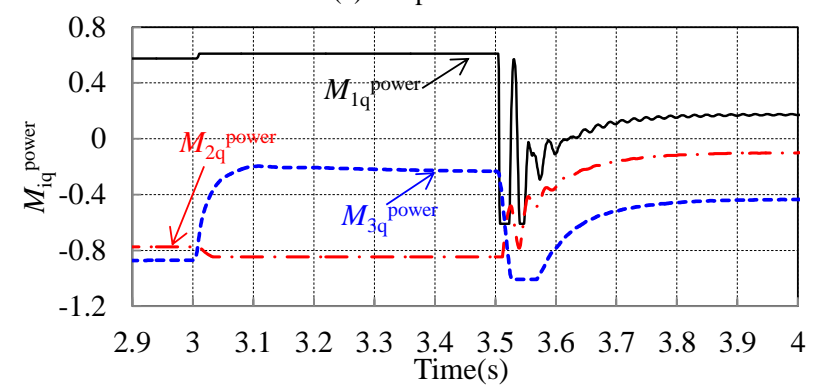

(c) $M_{\text {iq }}^{\text {power }}$

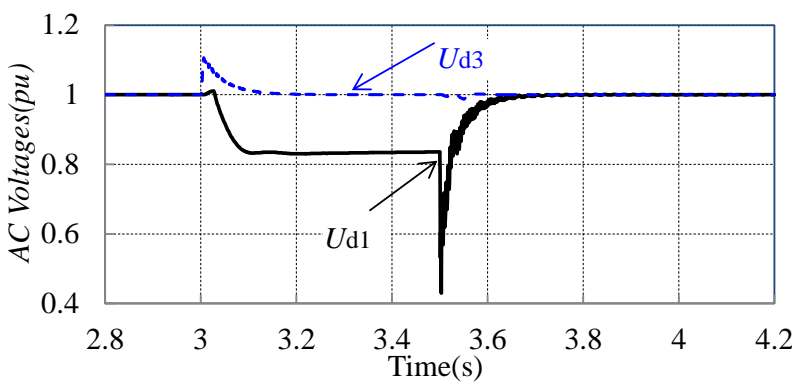

(b) AC voltages

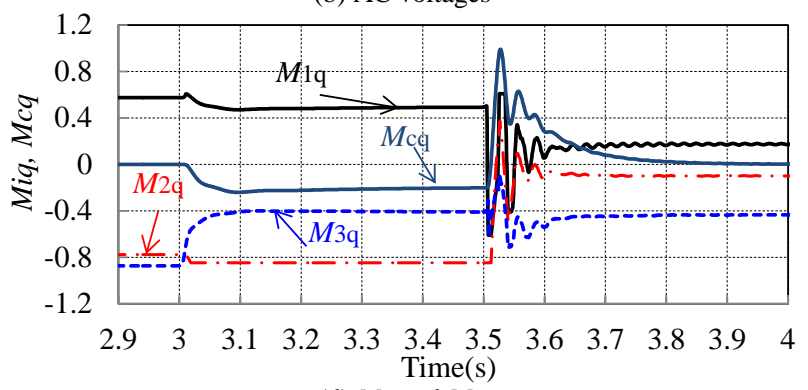

(d) $M_{\text {iq }}$ and $M_{\mathrm{cq}}$

Fig. 7. Response to VSC3 load step at $3.0 \mathrm{~s}$ and wind power step at $3.5 \mathrm{~s}$.

\subsection{Response to temporary and permanent faults}

Fig. 8 shows system response to temporary and permanent DC faults. A temporary DC fault with duration of $0.2 \mathrm{~s}$ is applied at DC terminal of port2 at 3.0s, on detecting $E_{2}$ lower than $0.7 \mathrm{pu}$, port2 is tripped from the hub by its AC CB. Operating time of the $\mathrm{AC} C \mathrm{CB}$ is set to be $0.05 \mathrm{~s}$. On detecting $E_{2}$ higher than $0.9 \mathrm{pu}, \mathrm{AC} \mathrm{CB}$ of port2 is re-closed. 
A further temporary DC fault with duration of $0.2 \mathrm{~s}$ is then applied at DC terminal of port3 at $4.0 \mathrm{~s}$; port 3 is tripped by its $\mathrm{AC} \mathrm{CB}$ at $4.05 \mathrm{~s}$ and reconnected to the hub at $4.25 \mathrm{~s}$. Another permanent DC fault is applied at DC terminal of port1 at $5.0 \mathrm{~s}$, and port1 is then tripped from the hub by its $\mathrm{AC} \mathrm{CB}$ at $5.05 \mathrm{~s}$.

Fig. 8(a)-(d) respectively show the DC power of the hub, DC voltages, capacitor voltages and AC voltages at VSC1 and VSC3.

During temporary DC fault at port2 (3.0-3.25s), $P_{\mathrm{dc} 2}$ drops to zero. Since there is temporary surplus injecting power, a temporary positive $V_{\mathrm{cq}}$ appears and is quickly controlled to zero. Fig. 8(d) shows the AC voltage of VSC1 temporary reduces to reduce the wind power transferred by VSC1. After removal the DC fault, the DC system is able to restore full power transfer capability.

During temporary DC fault at port3, DC voltage at port3 temporary drops to zero, $U_{\mathrm{d} 3}$ also temporary drops to zero. System is able to restore full power transfer capability after removal the fault at port3.

During DC fault at portl $(t>5 \mathrm{~s})$, there is surplus absorbing power immediately following the fault at port1 as both port 2 and port 3 are absorbing power from the hub before fault happens at port 1 and cannot abruptly change its power directions. There is temporary drop of $U_{\mathrm{d} 3}$ and $U_{\mathrm{d} 3}$ quickly restored to rated value. Port2 automatically reverses its power direction after portl has been tripped.

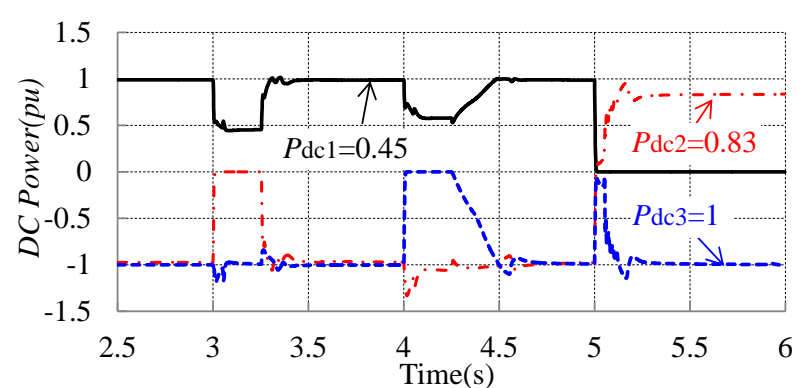

(a) DC power with temporary dc fault at port2

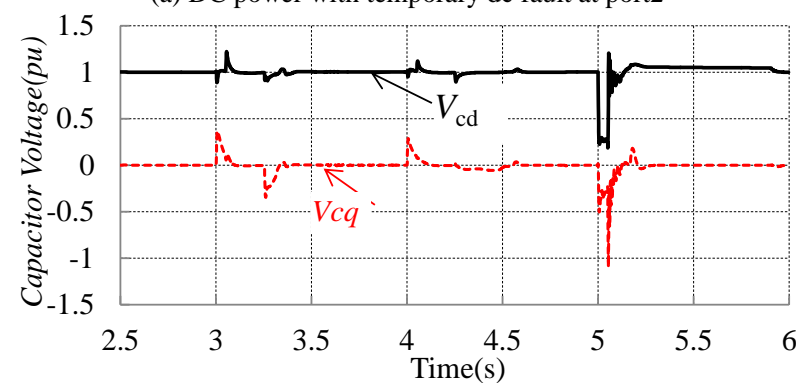

(c) Capacitor voltages

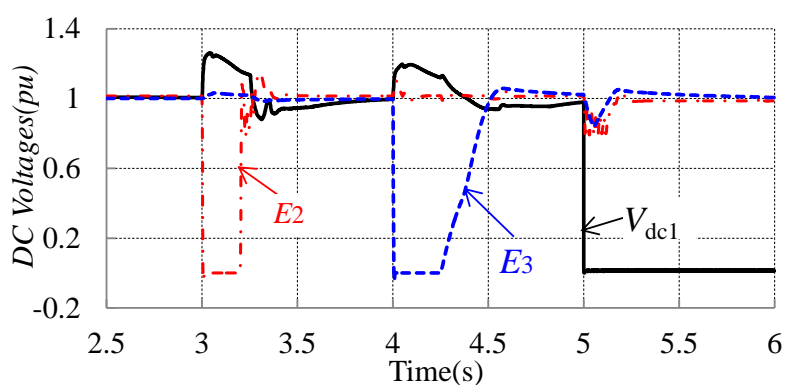

(b) DC voltages with temporary dc fault at port2

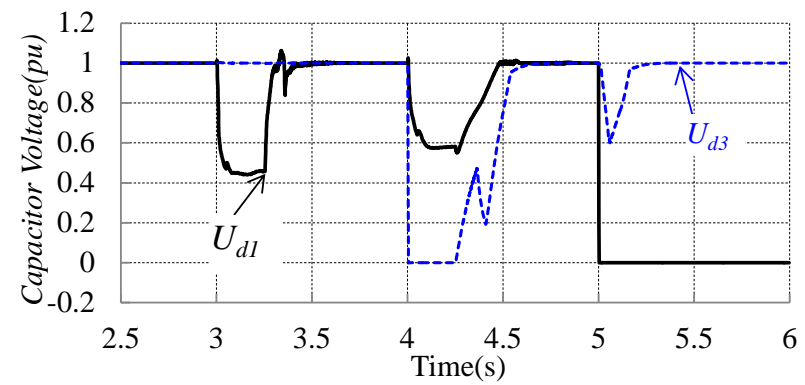

(d) AC voltages

Fig. 8. Response to temporary DC faults at Port2, Port3

\subsection{Response to malfunction of the AC CB of the hub(port2 DC fault)}


Fig. 9 shows response to malfunction of the AC CB of the hub. A permanent DC fault is applied at DC terminal of port2 at 3.0s and $\mathrm{AC} \mathrm{CB}$ of port2 fails to timely trip because of malfunction but trips $1 \mathrm{~s}$ after receiving the tripping command. The DC fault is therefore persistently applied at port 2 for $1 \mathrm{~s}$. IGBTs of port 2 remain in operation in this case since fault current remains below 2pu because of DC hub capability to inherently regulate fault current. If IGBTs are tripped the responses are similar as AC side of the hub is subjected to the same short circuit fault regardless of the tripping or operating of the IGBTs of the faulted port. .

Fig. 9(a) shows DC power of all the ports, we can see the hub retains power transfer capability even with persistent DC fault presented. Fig. 9(b) shows the DC voltages. DC terminal voltage at VSC1 is controlled at $1.05 \mathrm{pu}$, following the control strategy of Fig. 3(a).

Fig. 9(c) shows the $d$-axis capacitor voltage, $q$-axis capacitor voltage and magnitude of the capacitor voltage. $V_{\text {cd }}$ is lower than 1pu, as analyzed in (11). The capacitor voltage still retains high value and enables the remaining ports of the hub to continue to transfer power.

Fig. 9(d)-(f) show phase A AC current of port1-port3. We can see that there is no overcurrent at any port even with a DC fault persistently applied at one port. The hub can operate with high security even if there is malfunction of the $\mathrm{AC}$ CB.

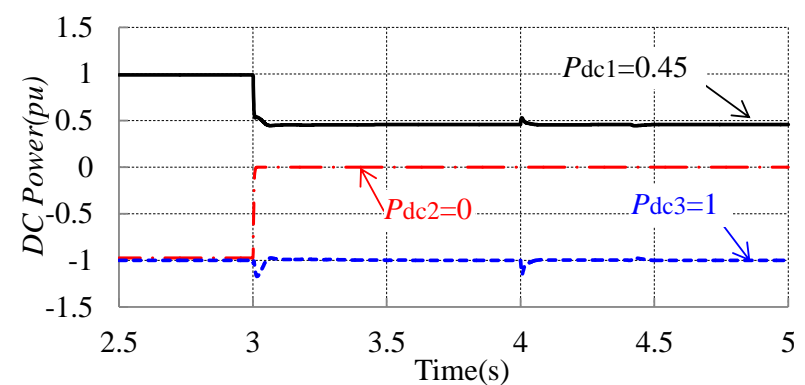

(a) DC power

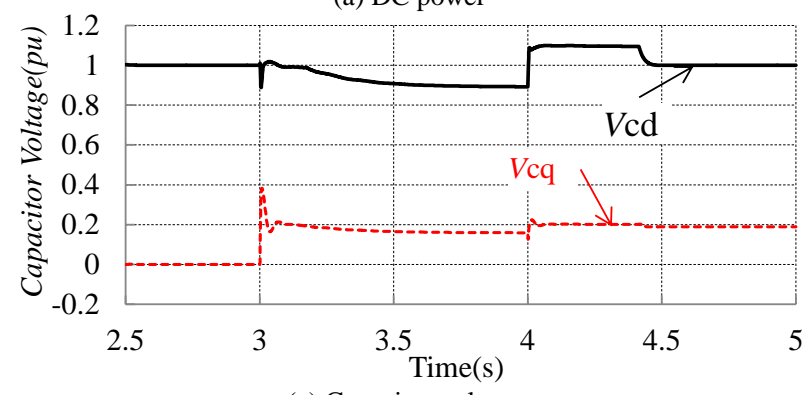

(c) Capacitor voltages

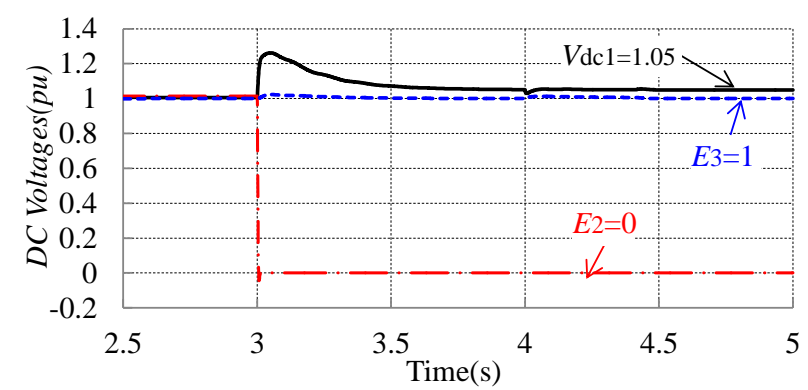

(b) DC voltages

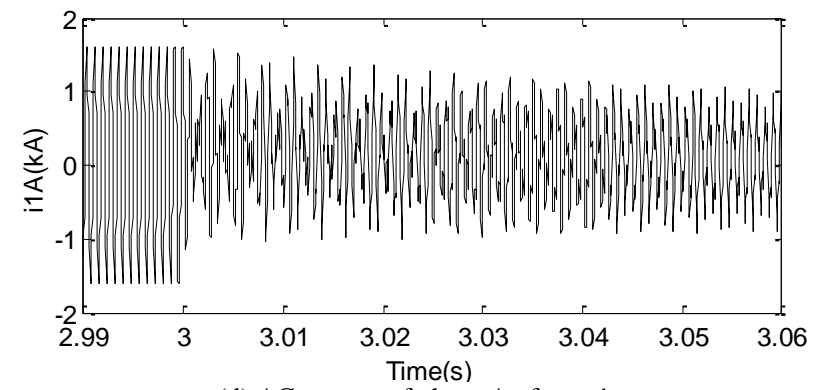

(d) AC current of phase A of port 1 


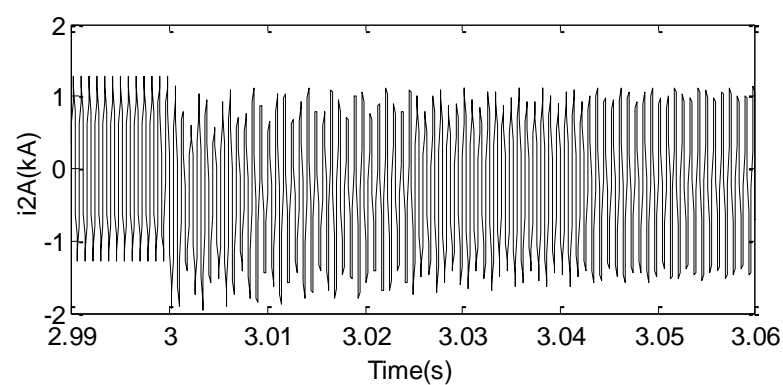

(e) AC current of phase A of port 2

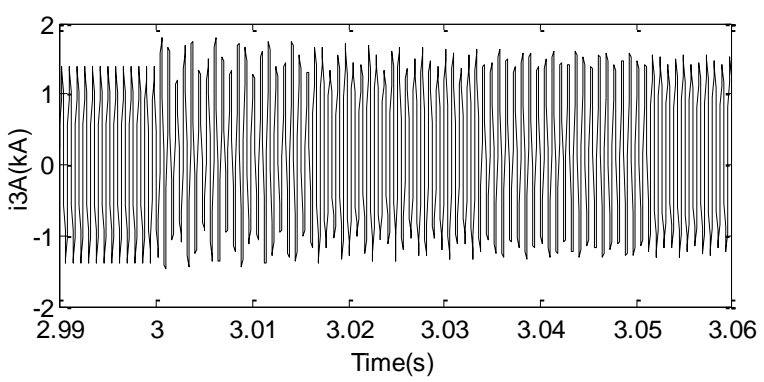

(f) AC current of phase A of port 3

Fig. 9. Response to malfunction of the AC CB of the hub.

\subsection{Operation under variable wind power}

Fig. 10 shows system response under variable wind power. Fig. 10(a) shows AC power of the 3 VSC converters where $P_{\text {ac1 }}$ is the wind power transferred by VSC1, $P_{\text {ac2 }}$ and $P_{\text {ac } 3}$ are respectively the active power absorbed by VSC2 and VSC3 from the DC grid. We can see the wind power variation is absorbed by $P_{\text {ac2 }}$, while $P_{\text {ac3 }}$ stays un-affected.

Fig. 10(b) shows the DC voltage at DC terminal of VSC1 and AC voltages at VSC1 and VSC3. We can see $V_{\text {dc1 }}$ stays below 1.05pu, since the power balancing control of Fig. 3(a) will not be activated during normal operation. There are $\mathrm{AC}$ voltage variations at VSC1 because of the wind power variation though $\mathrm{AC}$ voltage of VSC3 remains un-affected.

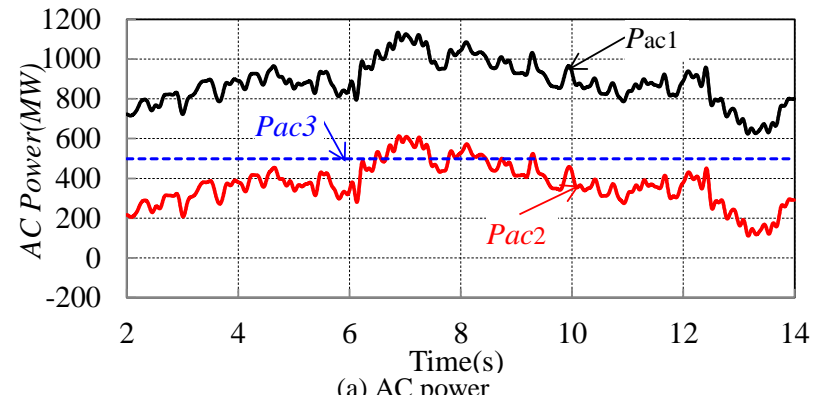

Fig. 10. Operation under variable wind power.

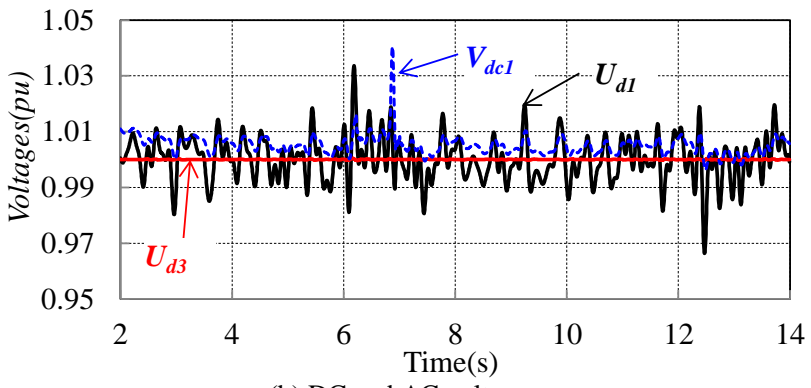

(b) DC and AC voltages

\section{Conclusion}

A control system for the steady-state and post-fault power management in a dc grid with LCL dc hub is proposed.

The automatic power balancing control at the VSC terminals and automatic power balancing control inside the LCL dc hub enables the whole dc grid to achieve fast power balancing even for extreme fault conditions. The designed power balancing controllers can be used as a highly reliable control method for the dc grid. It is shown that the power balancing controls remove the need of hardware dynamic braking choppers and resistors in a dc grid. The restarting sequence of the hub and the dc grid is developed which avoids any overvoltage even when connecting low voltage 
ports or starting a dead DC load with non-isolated LCL DC hub. The simulation results on a representative 3-terminal DC grid confirm all conclusions.

\section{Acknowledgement}

This project is funded by European Research Council under the Ideas program in FP7; grant no 259328, 2010.

\section{REFERENCES}

[1] Ahmed, N., Haider, A., Hertem, D., et al.: 'Prospects and challenges of future HVDC Super Grids with modular multilevel converters', Proc. $14^{\text {th }}$ EPE Conf. Appl., 2011, pp. 1-10.

[2] Häfner, J., Jacobson, B. 'Proactive Hybrid HVDC Breakers - A key innovation for reliable HVDC grids', CIGRE 2011 Bologna Symp., Sep 2012, pp. 1-9.

[3] Jovcic, D., Linden, K., Hertem, D., et al.: 'Feasibility of DC transmission Networks', Proc. ISGT Eur., 2011, pp. 1-8.

[4] Hertem, D., Ghandhari, M.: 'Multi-terminal VSC HVDC for the European Supergrid: obstacles', Renewable and Sustainable Energy Reviews, 2010, 14, (9), pp. 3156-3163.

[5] Dai, J., Phulpin, Y., Sarlette, A., et al: 'Coordinated primary frequency control among non-synchronous systems connected by a multi-terminal high-voltage direct current grid', IET Gener. Transm. Distrib., 2012, 6, (2), pp. 99-108..

[6] Zhu, J., Guerrero, J., Hung, W., et al.: 'Generic inertia emulation controller for multi-terminal voltage-source-converter high voltage direct current systems', IET Renew. Power Gener., 2014, 8, (7), pp. 740-748.

[7] Jovcic, D., Lin, W. :'Multiport high-power LCL DC hub for use in DC transmission grids’ IEEE Trans. Power Dei., 2014, 29, (3), pp. 760-768.

[8] Lin, W., Jovcic, D.: 'Reconfigurable multiphase multi GW LCL DC hub with high security and redundancy', Electric Power Systems Research, 2014, 110, pp. 104-112.

[9] Zhang, J., Jovcic, D., Lin, W.: 'Steady-state DC fault analysis of multiport DC hub’, EPE’14-ECCE Europe, 2014, pp. 1-10.

[10] Lüth, T., Merlin, M., Green, T., et al.: ‘High-frequency operation of a dc/ac/dc system for HVDC applications', IEEE Trans. Power Electron., 2015, 29, (8), pp. 4107-4115.

[11] Erlich, I., Bachmann, U.: 'Grid code requirements concerning connection and operation of wind turbines in Germany', IEEE PES General Meeting, 2005, pp. 1253-1257.

[12] Maneiro, J., Tennakoon, S., Barker, C. et al: 'Energy diverting converter topologies for hvde transmission systems', in $15^{\text {th }}$ European Conference on Power Electronics and Applications, 2013, pp. 1-10.

[13] Akhmatov, V., Callavik, M., Franck, C., et al: 'Technical guidelines and pre-standarization work for first HVDC grids', IEEE Trans. Power Del., 2014, 29(1), pp. 327-335.

[14] Vrionis, T., Koutiva, X., Vovos, N., et al: 'Control of an HVdc link connecting a wind farm to the grid for fault ride-through enhancement', IEEE Trans. Power Syst., 2007, 22, (4), pp. 2039-2047.

[15] Feltes, C., Wrede, H., Koch, F., et al: 'Enhanced fault ride-through method for wind farms connected to the grid through VSC-based HVDC transmission', IEEE Trans. Power Syst., 2009, 24, (3), pp. 1537-1546.

[16] Silva, B., Moreira, C., Leite, H., et al: 'Control strategies for AC fault ride through in multiterminal HVDC grids', IEEE Trans. Power Deli., 2014, 29, (1), pp. 395-405. 
[17] Callavik, M., Schettler, F., Debry, M., et al: 'Roadmap to the supergrid technologies', 2013. [Online]. Available: www.friendsofthesupergrid.eu.

[18] Guo, C., Zhao, C., 'Supply of an entirely passive AC network through a double-infeed HVDC system', IEEE Trans. Power Electron., 2010, 24, (11), pp. 2835-2841.

[19] Engel, S., Stieneker, M., Soltau, N., et al: 'Comparison of the modular multilevel dc converter and the dual active bridge converter for power conversion in HVDC and MVDC grids', IEEE Trans. Power Electron., 2015, 30, (1), pp. 124-137.

[20] Lin, W., Wen, J., Liang, J., et al: ‘A three-terminal HVDC system to bundle wind farms with conventional power plants', IEEE Trans. Power Syst., 2013, 28, (3), pp. 2292-2300.

[21] Tapia, A, Tapia, G., Ostolaza, J., et al: 'Modeling and control of a wind turbine driven doubly fed induction generator', IEEE Trans. Energy Convers.2003, 18, (2), pp. 194-204.

[22] Chinchilla, M., Arnaltes, S., Burgos, J.: 'Control of permanent-magnet generators applied to variable-speed wind-energy systems connected to the grid', IEEE Trans. Energy Convers. 2006, 21, (1), pp. 130-135.

[23] Hierons, R. 'Generating complete controllable test suites for distributed testing', IEEE Trans. Softw. Eng., 2015, 41, (3), pp. $279-293$. 